\title{
COVID-19 presenting with Ophthalmoplegia in a patient with Acute Kidney Injury
}

\author{
Pauline Francisca Gomes ${ }^{1 *}$, Abdul Basit Ibne Momen², Amrin Sultana ${ }^{3}$, Rafa Faaria Alam³, Sadia Saber ${ }^{3}$, \\ Mohammed Tarek Alam ${ }^{4}$ \\ DOI: https://doi.org/10.3329/bccj.v9i1.53062
}

\begin{abstract}
:
COVID-19 has proved to cause multi-systemic manifestations in many reported cases across the world. Here, we report a rare presentation of a 20 years old COVID-19 positive male patient with acute kidney injury who developed ophthalmoplegia during the course of the disease. COVID-19 being a relatively new disease, its neurological manifestation is even rarer with limited literature concerning the symptoms. Clinicians should, therefore, have a high suspicion and awareness regarding the many faces of the severe acute respiratory syndrome coronavirus-2(SARS-CoV-2), for early detection and mitigation of the disease, especially during the pandemic.
\end{abstract}

Key words: COVID-19, Ophthalmoplegia.

\section{Background:}

Two decades into the $21^{\text {st }}$ century and the world have already witnessed life-threatening manifestations of the coronaviruses thrice: the severe acute respiratory syndrome (SARS) by the SARS-CoV in 2002-2003, the Middle East respiratory syndrome (MERS) by the MERS-CoV in 2012, and Coronavirus disease 2019 (COVID-19) by the SARS-CoV-2 currently surging across the globe. However, unlike the other two coronaviruses, SARS-CoV-2 causes multi-systemic symptoms of variegated severity. The primary manifestations of COVID-19 typically include fever, cough, diarrhea and fatigue which eventually progresses to life-threatening respiratory distress in severe cases. Based on epidemiological survey on COVID-19, the median time from the first symptoms to dyspnea was 5 days, to hospital admission was 7 days and to intensive care was 8 days ${ }^{1}$. Its latency has facilitated the dissemination of the virus across multiple organs. Among its various other systemic involvements, neurologic symptoms of the virus, such as headache, dizziness, impaired consciousness, impairment of taste and smell, acute cerebrovascular disease have been reported in $36.4 \%$ of hospitalized patients as documented by a retrospective, observational case series conducted in 3 special care COVID-19 centers within the period of January to February 2020 in Wuhan, China ${ }^{2}$. Another retrospective case

1. Research Fellow, Shomman Foundation, Dhaka, Bangladesh.

2. Registrar, Department of Medicine, Bangladesh Medical College.

3. Assistant Registrar, Department of Medicine, Bangladesh Medical College.

4. Professor and Head of Department of Medicine, Bangladesh Medical College.

*Corresponding Author:

Dr. Pauline Francisca Gomes

Research Fellow

Shomman Foundation, Dhaka, Bangladesh.

Email: pauline2f4gomes@gmail.com series conducted at a hospital center in Hubei, China showed that $31.6 \%$ of COVID-19 positive patients had ocular manifestations consistent with conjunctivitis, including conjunctival hyperemia, epiphora, chemosis and increased secretions ${ }^{3}$. Moreover, patients with COVID-19 infection and ophthalmoplegia in the setting of Miller Fisher Syndrome have also been reported ${ }^{4,5}$. A case of abducent nerve palsy with features of binocular horizontal diplopia in a COVID-19 positive patient was also reported on June $2020^{6}$. Here we present a rare case of a patient who demonstrated symptoms of ophthalmoplegia in the setting of RT-PCR positive COVID-19. However, prior to confirmed diagnosis, the patient was initially admitted with symptoms of acute kidney injury which raised the suspicion for leptospirosis.

\section{Case presentation:}

20 years old previously healthy man was admitted to Bangladesh Medical College Hospital, Dhaka with complains of generalized swelling for 15 days, scanty and painful micturition with dark colored urine for 5 days. While under the supervision of Nephrology department, his laboratory investigations revealed low haemoglobin $(10.9 \mathrm{~g} / \mathrm{dl})$, raised WBC count $\left(25,500 / \mathrm{mm}^{3}\right)$, neutrophil $(89 \%)$, ESR $(31 \mathrm{~mm}$ in first hour), serum creatinine (10.28mg/dl), ALT (116 U/L), urea $(271.6 \mathrm{mg} / \mathrm{dl})$, as shown on Table 1(on admission). His urine routine examination showed presence of albumin $(+++)$, granular $(+)$ and hyaline casts $(+)$. His ultrasound of whole abdomen showed acute nephropathy with hepato-splenomegaly, cystitis and bilateral minimal pleural effusion. Then, 3 days after his admission, the patient developed fever $\left(102^{\circ} \mathrm{F}\right)$. Considering aforementioned scenario, with high suspicion of leptospirosis, patient was transferred to the Medicine department for further management.

We then sent RT-PCR for COVID-19 which was positive. His anti-leptospira $\operatorname{IgG}$ and $\operatorname{IgM}$ on immunochromatography came negative. His urine and blood culture showed no growth of any organism. On further investigation, his CRP was $24 \mathrm{mg} / 1$ (normal $<6 \mathrm{mg} / \mathrm{l}$ ), ferritin was more than $1500 \mathrm{ng} / \mathrm{ml}$ (normal $32-397 \mathrm{ng} / \mathrm{ml}$ ) and D-dimer was raised to $6.84 \mu \mathrm{g} / \mathrm{ml}$ 
(normal $<0.50 \mu \mathrm{g} / \mathrm{ml}$ ). His chest X-ray showed bilateral peripheral patchy opacities with cardiomegaly. On the $5^{\text {th }}$ day from the onset of fever, he developed unilateral diplopia and squint (left eye). On examination, patient was found to have left abducens nerve palsy, as shown in Figure 1 (Before Treatment). He did not complain of pain with eye movements, ptosis or any other neurological symptoms such as paraesthesia, anosmia or ataxia.

On the basis of physical findings and lab results, diagnosis of COVID-19 with acute kidney injury and ophthalmoplegia was made. He was treated with oral Ivermectin, oral Doxycycline (and IV Meropenem for 10 days along with other symptomatic management. For his ocular complains he was given Dexamethasone eye drop (one drop on affected eye 4 times daily). Over the course of 10 days, since the initiation of treatment, his temperature demonstrated a decreasing spike and eventually subsided. His laboratory reports showed decreased WBC count $\left(13,720 / \mathrm{mm}^{3}\right)$, serum creatinine $(0.58$ $\mathrm{mg} / \mathrm{dl})$ and urea $(31.6 \mathrm{mg} / \mathrm{dl})$, as shown on Table 1(on discharge). The patient was discharged with advice to continue Dexamethasone eye drop and was scheduled for a follow-up with MRI-brain report after 7 days. On the day of follow-up, patient's eye complication had resolved as shown in Figure 1 (After treatment). His MRI-brain report was normal.

Table 1: Laboratory findings on admission and on discharge

\begin{tabular}{|c|c|c|c|}
\hline Laboratory findings & $\begin{array}{c}\text { Normal } \\
\text { Value }\end{array}$ & $\begin{array}{c}\text { On } \\
\text { admission dí }\end{array}$ & $\begin{array}{c}\text { On } \\
\text { discharge }\end{array}$ \\
\hline WBC $\left(/ \mathrm{mm}^{3}\right)$ & $4000-11,000$ & 25,500 & 13,720 \\
\hline Neutrophil (\%) & $40-70$ & 89 & 66 \\
\hline Lymphocyte (\%) & $20-50$ & 6 & 27 \\
\hline Haemoglobin (g/dl) & $13-18$ & 10.9 & 11.0 \\
\hline Platelet (x 109/1) & $150-400$ & 150 & 350 \\
\hline ESR ( $\mathrm{mm}$ in $1^{\text {st }}$ hour) & $0-10$ & 31 & 90 \\
\hline Serum creatinine $(\mathrm{mg} / \mathrm{dl})$ & $0.6-1.3$ & 10.28 & 0.58 \\
\hline Urea (mg/dl) & $10-50$ & 271.6 & 31.6 \\
\hline ALT (U/1) & $10-40$ & 116 & 105.1 \\
\hline
\end{tabular}

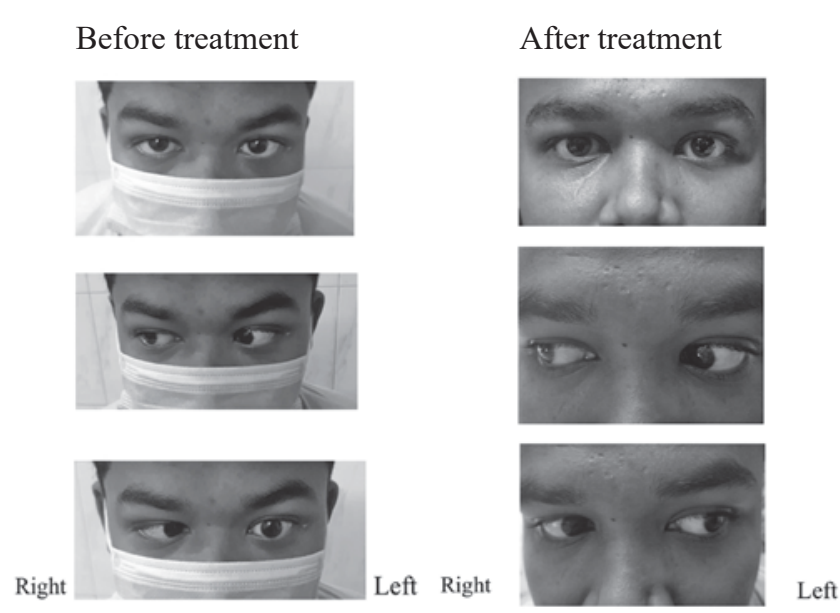

Figure 1: Ocular findings before treatment and after treatment.

\section{Discussion:}

SARs-CoV-2 is a large enveloped non-segmented positive -sense RNA virus. Its entry into the human host is believed to be via the cellular receptor angiotensin- converting- enzyme 2 (ACE-2) which is expressed in human airway epithelia, lung parenchyma, vascular endothelia, kidney, small intestine and neurologic tracts ${ }^{7}$. The COVID-19 virus uses a spike protein $\mathrm{S} 1$ that enables its attachment to the cell membrane by interacting with host ACE2 receptor. Although the exact mechanism of neuro-invasiveness of the virus is not yet known, many pathways have been proposed. Similar to SARS-CoV, the COVID-19 virus enters through the cribriform plate of the ethmoid close to the olfactory bulb that leads to cerebral involvement, a phenomenon strongly backed up by symptoms of hyposmia in many patients. Also, the presence of the virus in the general circulation enables it to enter the cerebral circulation following a pathway facilitated by the sluggish movement of the blood in the microcirculation. Subsequently, the virus causes damage to the endothelial lining which favors the viral access to the brain. Moreover, autopsy findings of patients with SARS-CoV infections have shown presence of the viral nucleic acids in the cerebrospinal fluid and brain tissue ${ }^{8}$. An article published in May 2020 by Vonck and colleagues proposed that the neurological symptoms in COVID-19 patients can be due to direct viral neurological injury or indirect neuro-inflammatory and autoimmune mechanism? However, the exact neurotropic potential of the virus in infected patients is yet to be established due to the lack of adequate evidence.

Ophthalmoplegia is the paralysis or weakness of the muscles of the eye which leads to the symptoms of diplopia, blurry vision and/or squint. The condition is widely classified into two types: chronic progressive external ophthalmoplegia and internal ophthalmoplegia ${ }^{10}$. Major causes leading to this condition include nerve damage by infection, multiple sclerosis, stroke, head trauma, brain tumor, diabetes, myasthenia gravis and Graves' disease. We hypothesize that in our patient either a direct or indirect virally mediated neurological injury led to weakness of ocular muscles as evidenced by the patient's symptoms. Moreover, the lack of pre-existing conditions such as diabetes, Graves' disease or evidence of trauma, tumor or absence of predisposing risk factors to stroke, aids in the exclusion of other causes of ophthalmoplegia. Also, the resolution of ocular symptoms within a week after treating the underlying infection caused by SARS-CoV-2 strongly depicts the association of the virus with ophthalmoplegia.

A probable differential diagnosis for this case was leptospirosis. The patient was admitted with symptoms of acute kidney injury, mild anemia on complete blood count with ultrasound of whole abdomen showing acute nephropathy, hepatosplenomegaly and minimal pleural effusion. He also developed fever and his X-ray findings showed lung infiltrates. All of these findings were consistent with leptospirosis ${ }^{11}$. Moreover, the development of ocular complications during the course of the disease was also 
pointing towards leptospirosis. Some of the commonly found ocular findings in leptospirosis are conjunctival congestion, scleral icterus, keratitis, uveitis, retinal vasculitis, cranial nerve palsies and optic neuropathy ${ }^{12}$. However, the differential diagnosis was excluded due to the lab findings which showed negative anti-leptospira antibody, negative blood and urine culture. Furthermore, the positive COVID-19 RT-PCR, with raised CRP, ESR, ferritin and D-dimer levels were suggestive of COVID related ocular complications.

\section{Conclusion:}

This report portrays that as COVID-19 still remains a perplexing disease worldwide, it is crucial to recognize its many faces, one of them being its neurotropic potential. For early detection and prevention of transmission of the deadly virus, it is highly recommended for doctors to familiarize themselves with the neurologic spectrum of the disease.

\section{Reference:}

1. Li Y-C, Bai W-Z, Hashikawa T. The neuroinvasive potential of SARS-CoV2 may play a role in the respiratory failure of COVID-19 patients. Journal of Medical Virology. 2020;92(6):552-5.

2. Mao L, Jin H, Wang M, Hu Y, Chen S, He Q et al. Neurologic Manifestations of Hospitalized Patients With Coronavirus Disease 2019 in Wuhan, China. JAMA Neurology. 2020;77(6):683-90.

3. Wu P, Duan F, Luo C, Liu Q, Qu X, Liang L et al. Characteristics of Ocular Findings of Patients With Coronavirus Disease 2019 (COVID-19) in Hubei Province, China. JAMA ophthalmology.
2020;138(5):575-8.

4. Rana S, Lima AA, Chandra R, Valeriano J, Desai T, Freiberg W et al. Novel Coronavirus (COVID-19)-Associated Guillain-Barré Syndrome: Case Report. J Clin Neuromuscul Dis. 2020;21(4):240-2

5. Lantos JE, Strauss SB, Lin E. COVID-19-Associated Miller Fisher Syndrome: MRI Findings. American Journal of Neuroradiology. 2020; 41(7):1184-1186

6. Falcone MM, Rong AJ, Salazar H, Redick DW, Falcone S, Cavuoto KM. Acute abducens nerve palsy in a patient with the novel coronavirus disease (COVID-19). Journal of American Association for Pediatric Ophthalmology and Strabismus. 2020; 24(4):216-217

7. Donoghue $\mathrm{M}$, Hsieh F, Baronas E, Godbout K, Gosselin M, Stagliano N, et al. A Novel Angiotensin-Converting Enzyme-Related Carboxypeptidase (ACE2) Converts Angiotensin I to Angiotensin 1-9. Circulation Research. 2000;87(5):E1-9.

8. Baig AM, Khaleeq A, Ali U, Syeda H. Evidence of the COVID-19 Virus Targeting the CNS: Tissue Distribution, Host-Virus Interaction, and Proposed Neurotropic Mechanisms. ACS Chemical Neuroscience. 2020;11(7):995-8.

9. Vonck K, Garrez I, De Herdt V, Hemelsoet D, Laureys G, Raedt R, et al. Neurological manifestations and neuro-invasive mechanisms of the severe acute respiratory syndrome coronavirus type 2 . European Journal of Neurology. 2020;27(8):1578-87.

10. Lavin P. Ophthalmoplegia. In: Aminoff MJ, Daroff RB, editors. Encyclopedia of the Neurological Sciences (Second Edition). Oxford: Academic Press; 2014. p. 651-2.

11. Levett PN. Leptospirosis. Clinical Microbiology Reviews. 2001;14(2):296-326.

12. Rathinam S. Ocular manifestations of leptospirosis. Journal of Postgraduate Medicine. 2005;51(3):189-94. 